\title{
Asthma and other pulmonary diseases in former elite athletes
}

\author{
Urho M Kujala, Seppo Sarna, Jaakko Kaprio, Markku Koskenvuo
}

\begin{abstract}
Background - The prevalence of asthma is rising and there are recent reports of increasing asthma rates among top level skiers and runners in the Nordic countries. Methods - The lifetime occurrence of pulmonary diseases (asthma, chronic bronchitis, emphysema) and current bronchitis symptoms was compared in former elite male athletes $(n=1282)$ who represented Finland between 1920 and 1965 at least once in international competitions and controls $(n=777)$ who, at the age of 20 , were classified as healthy and who responded to a questionnaire in 1985 . The presence of disease and symptoms was identified from the questionnaire and, in the case of asthma, also from a nationwide reimbursable medication register. The death certificates of the subjects of our original cohort who died between 1936 and 1985 were also investigated to determine the cause of death.
\end{abstract}

Results - The occurrence of the pulmonary diseases was associated with age, smoking habits, occupational group, and a history of exposure to chemicals. After adjusting for these variables, athletes who participated in mixed sports (odds ratio (OR) $0.46,95 \%$ confidence interval (CI) 0.23 to 0.92 ) and power sports (OR $0.43,95 \% \mathrm{CI}$ 0.21 to 0.87 ) had lower odds ratios for emphysema, and endurance sports athletes had a lower odds ratio for the presence of at least one pulmonary disease (OR $0.53,95 \%$ CI 0.28 to 0.98 ) when compared with controls. Athletes also tended to have fewer reimbursable medications for asthma and fewer current symptoms for chronic bronchitis. Between 1936 and 1985 two controls but none of the athletes died of asthma.

Conclusions - The lifetime occurrence of asthma or other pulmonary diseases is not increased in former elite athletes, and exercise alone, even in a cold environment, did not appear to increase the prevalence of asthma, at least up to the mid $1980 \mathrm{~s}$.

(Thorax 1996;51:288-292)

Keywords: asthma, pulmonary diseases, sports.

There is no clear evidence that strenuous physical training in itself increases the risk of asthma-like symptoms ${ }^{1-3}$ although exposure to cold and dry air in competitive athletes may increase the risk. ${ }^{45}$ Reports of high use of asthma medication among cross country skiers have raised the question of whether asthma is more common among skiers than other athletes or whether skiers use the drugs to enhance performance. ${ }^{5}$ Studies of both Swedish ${ }^{5}$ and Norwegian ${ }^{6}$ skiers revealed greater frequencies of asthma symptoms and use of anti-asthmatic medication compared with controls. In addition, $53 \%$ of runners from the Finnish junior and adult national teams reported asthma symptoms, while among runners in the Nordic countries generally, allergy and exposure to aeroallergens during the pollen season in spring and indoor training in winter may also be responsible for provoking asthma-like symptoms. ${ }^{7}$ Larsson et $a l^{5}$ hypothesised that exposure to cold air may lead to both a transient increase in bronchial responsiveness and to persistent asthma as increased bronchial responsiveness was present to the same degree in both summer and winter among cross country skiers, although none had had asthma diagnosed since childhood. However, $\mathrm{Heir}^{8}$ reported that bronchial responsiveness to methacholine was higher in winter than in summer among Norwegian skiers.

To test the hypothesis that strenuous training at low temperatures in itself could be pathogenic for asthma or other pulmonary diseases, we investigated the lifetime occurrence of pulmonary diseases among former Finnish elite athletes with a history of prolonged competitive physical activity who had competed before $\beta_{2}$ agonists were available. The endurance athlete group comprised cross country skiers and runners exposed to cold air during training and races in the winter season. Current questionnaires or interviews of athletes may be biased because the high prevalence of asthma among competitive skiers has become a widely discussed topic in the popular media in Finland. Moreover, regular use of $\beta_{2}$ agonists may lead to increased bronchial responsiveness. ${ }^{9} \mathrm{We}$ thus analysed questionnaire data from a study on Finnish male ex-athletes and controls carried out in 1985. Endurance, mixed sports, and power sports athletes were studied, together with controls who had been healthy at the age of 20 and were matched for age and area of residence with the athletes.

\section{Methods}

Male athletes who had represented Finland between the years 1920-1965 at least once at the Olympic games, World or European championships or other international competitions were identified from multiple sources. ${ }^{10}$ For $85 \%$ of the athletes traced controls were selected from among Finnish men 
Table 1 Study groups at 1 fanuary 1985 and number (\%) of subjects responding to the 1985 questionnaire

\begin{tabular}{lcr}
\hline Sports & $\begin{array}{l}\text { Group size in } \\
\text { 1985, address } \\
\text { identified }\end{array}$ & $\begin{array}{l}\text { No (\%) } \\
\text { answering } \\
\text { questionnaire in } \\
1985\end{array}$ \\
\hline Endurance sports & 205 & $175(85 \cdot 4)$ \\
Long distance running & 125 & $103(82 \cdot 4)$ \\
Cross country skiing & 80 & $72(90 \cdot 0)$ \\
Mixed sports & 781 & $664(85 \cdot 0)$ \\
Soccer & 193 & $159(82 \cdot 4)$ \\
Ice hockey & 131 & $112(85 \cdot 5)$ \\
Basketball & 77 & $68(88 \cdot 3)$ \\
Other track and field* & 380 & $325(85 \cdot 5)$ \\
Power sports & 532 & $443(83 \cdot 3)$ \\
Boxing & 164 & $136(82 \cdot 9)$ \\
Wrestling & 165 & $141(85 \cdot 5)$ \\
Weight lifting & 83 & $67(80 \cdot 7)$ \\
Track and field throwers & 120 & $99(82 \cdot 5)$ \\
Total & 1518 & $1282(84 \cdot 7)$ \\
Controls & 1010 & $777(76 \cdot 9)$ \\
\hline
\end{tabular}

* Includes jumpers, sprinters, hurdlers, middle distance runners, and decathletes.

who, at the age of 20 , were completely healthy (class AI, fully fit for ordinary military service) at the medical examination preceding their conscription. They were drawn from the public register archives of men liable for military service and matched for birth cohort and area of residence with the athletes. The control group was identified in 1978-9 and no controls for athletes traced later (hockey players, basketball players, weight lifters) were obtained. The original cohort of athletes comprised 2401 men and the control group 1712. The control group did not include elite athletes but physically active subjects were not excluded. In 1985 a questionnaire was sent to those who were still alive and whose address could be identified to obtain historical data, and the subjects who completed and returned the questionnaire (1282 athletes and 777 controls) formed the basis of the study (table 1). The response rate among those who were alive in 1985 and whose address could be identified was $77 \%$ for controls and $80-90 \%$ by sport for the athletes. We grouped the sports according to the type of training ${ }^{1011}$ needed to achieve maximal results - that is, endurance sports $(n=175)$, power sports $(n=443)$, and mixed sports (mostly team games; $n=664)$.

\section{QUESTIONNAIRE}

The 1985 questionnaire contained items on sociodemographic factors (including occupation and work related factors), smoking, physical activity, discontinuation of sporting career, and occurrence of bronchial symptoms and of certain diseases verified by doctors.

To determine whether the subjects had a lifetime history of the disease the questionnaire asked: "Has a doctor said that you have or have ever had (i) asthma, (ii) chronic bronchitis, or (iii) emphysema?" If the subject confirmed at least one of these disorders he was considered to have pulmonary disease. Similarly, the subjects were asked if they had ever suffered from allergic rhinitis such as hay fever.

Any current bronchial symptoms were recorded based on questions designed according to the 1966 version of the MRC Questionnaire for Respiratory Symptoms. ${ }^{12}$ The respondent was classified as having a current chronic productive cough if he had coughed up phlegm on most days for at least three months during the previous year.

\section{REIMBURSABLE MEDICATION DATA}

The cumulative incidence of asthma, based on reimbursable medication data obtained from the register of the Social Insurance Institution (the public agency responsible for basic social security in Finland), was also assessed. The national health insurance scheme covers all residents of Finland irrespective of age and place of residence. Our check through the records only dated back to 1970 , although medications started earlier were also included. During our study either $90 \%$ or $100 \%$ of the costs of prescription drugs approved for the medication of asthma were reimbursable. To qualify for the refund the patient had to submit a medical certificate (issued by a physician) describing the illness and the need for drug therapy. The application was then assessed by the Social Insurance Institution according to uniform minimum criteria and reviewed by their specialists. ${ }^{13}$ The validity of the register is therefore very high. The occurrence of asthma was analysed from the register of cases diagnosed up to December 1985.

\section{DEATH CERTIFICATES}

Copies of death certificates of the original study cohort were obtained for the years 1936-1985 using the files of the Cause of Death Bureau at the Central Statistical Office of Finland with their permission.

\section{CONFOUNDING FACTORS}

Occupational data were collected partly from the Central Population Registry and partly from the 1985 questionnaire study and were classified into the following categories: executives, clerical staff, skilled workers, unskilled workers, and farmers. ${ }^{14}$ Each person was classified according to his longest occupation.

Tobacco smoking status was classified from responses to a detailed smoking history. ${ }^{15}$ Never smokers had smoked no more than 5-10 packs of cigarettes (or equivalent in another tobacco product) in their lifetime. Other subjects were classified as current smokers or ex-smokers according to whether they were smoking daily or almost daily at the time of the questionnaire, or had quit. The age of quitting was recorded.

Exposure to chemicals was classified from the subjects' reports of contact at work or at their hobbies with chemical liquids or gases and fell into three categories: lifetime exposure of less than one month, one month to four years, and more than four years.

\section{DATA ANALYSIS}

Odds ratios (OR) for the presence of disease and their $95 \%$ confidence intervals $(95 \% \mathrm{CI})$ for different athletic groups compared with 
Table 2 Lifetime occurrence (\%)* of physician diagnosed asthma, chronic bronchitis, emphysema, allergic rhinitis, and current chronic productive cough in different study groups

\begin{tabular}{|c|c|c|c|c|c|}
\hline Sport & Asthma & Chronic bronchitis & Emphysema & Allergic rhinitis & $\begin{array}{l}\text { Current chronic } \\
\text { productive cough }\end{array}$ \\
\hline $\begin{array}{l}\text { Endurance sports } \\
\text { Long distance running } \\
\text { Cross country skiing }\end{array}$ & $\begin{array}{l}2 \cdot 9(5) \\
2 \cdot 0(2) \\
4 \cdot 3(3)\end{array}$ & $\begin{array}{l}5 \cdot 3(9) \\
7.9(8) \\
1.4(1)\end{array}$ & $\begin{array}{l}5 \cdot 3(9) \\
4 \cdot 0(4) \\
7 \cdot 1(5)\end{array}$ & $\begin{array}{l}11 \cdot 1(19) \\
10.9(11) \\
11.4(8)\end{array}$ & $\begin{array}{l}2 \cdot 3(4) \\
1.9(2) \\
2 \cdot 8(2)\end{array}$ \\
\hline $\begin{array}{l}\text { Mixed sports } \\
\text { Soccer } \\
\text { Ice hockey } \\
\text { Basketball } \\
\text { Other track and field }\end{array}$ & $\begin{array}{l}2 \cdot 3(15) \\
0 \cdot 6(1) \\
2 \cdot 7(3) \\
3 \cdot 0(2) \\
2 \cdot 8(9)\end{array}$ & $\begin{array}{l}8 \cdot 3(54) \\
7 \cdot 1(11) \\
9 \cdot 8(11) \\
4 \cdot 5(3) \\
9 \cdot 1(29)\end{array}$ & $\begin{array}{l}2.4(16) \\
4.5(7) \\
0.9(1) \\
3.0(2) \\
1.9(6)\end{array}$ & $\begin{aligned} 11 \cdot 9(78) \\
9 \cdot 0(14) \\
8.0(9) \\
6.0(4) \\
16.0(51)\end{aligned}$ & $\begin{array}{l}2 \cdot 1(14) \\
1 \cdot 9(3) \\
1 \cdot 8(2) \\
2 \cdot 9(2) \\
2 \cdot 2(7)\end{array}$ \\
\hline $\begin{array}{l}\text { Power sports } \\
\text { Boxing } \\
\text { Wrestling } \\
\text { Weight lifting } \\
\text { Track and field throwers }\end{array}$ & $\begin{array}{l}2 \cdot 3(10) \\
3 \cdot 8(5) \\
2 \cdot 2(3) \\
1 \cdot 5(1) \\
1 \cdot 0(1)\end{array}$ & $\begin{array}{r}9 \cdot 2(40) \\
10 \cdot 7(14) \\
7 \cdot 2(10) \\
6 \cdot 1(4) \\
12 \cdot 4(12)\end{array}$ & $\begin{array}{l}3 \cdot 7(16) \\
3 \cdot 8(5) \\
4 \cdot 3(6) \\
3 \cdot 0(2) \\
3 \cdot 1(3)\end{array}$ & $\begin{array}{r}9 \cdot 0(39) \\
9 \cdot 2(12) \\
10 \cdot 1(14) \\
10 \cdot 6(7) \\
6 \cdot 2(6)\end{array}$ & $\begin{array}{l}3 \cdot 7(16) \\
5 \cdot 3(7) \\
3 \cdot 6(5) \\
3 \cdot 1(2) \\
2 \cdot 0(2)\end{array}$ \\
\hline Total & $2 \cdot 4(30)$ & $8 \cdot 2(103)$ & $3 \cdot 3(41)$ & $10 \cdot 6(136)$ & $2 \cdot 7(34)$ \\
\hline Controls & $3 \cdot 5(27)$ & $10 \cdot 5(80)$ & $6.5(50)$ & $10 \cdot 6(81)$ & $6 \cdot 0(46)$ \\
\hline
\end{tabular}

Values in parentheses are numbers of subjects.

* When calculating the percentages those subjects not answering the specific question were ignored

controls were analysed using logistic regression models (BMDP Statistical Software). Age, smoking, occupational group, and exposure to chemicals were included as potential confounding factors in the analysis.

\section{Results}

The occurrence of asthma, chronic bronchitis, emphysema, and allergic rhinitis as diagnosed by a physician, as well as the prevalence of current chronic productive cough in different study groups, are shown in table 2 . There were no differences in the incidence of allergic rhinitis (hay fever). Twenty seven subjects (14\%) with a history of diagnosed chronic bronchitis reported a current chronic productive cough compared with $54(2 \cdot 7 \%)$ of those without such a history. At least one pulmonary disease (asthma, chronic bronchitis, or emphysema) was found in 18 of $171(10.5 \%)$ endurance athletes, 77 of $654(11.8 \%)$ mixed sports athletes, 56 of $433(12.9 \%)$ power sports athletes, and 125 of $765(16.3 \%)$ controls.

The age adjusted odds ratios of the various pulmonary diseases and current chronic productive cough compared with controls are shown in table 3 . The endurance sports athletes had a lower age adjusted odds ratio for chronic bronchitis, while mixed sports and power sports athletes had lower odds ratios for emphysema (table 3). Compared with controls, the age adjusted odds ratios for at least one pulmonary disease (asthma, chronic bronchitis, emphysema) were 0.47 (95\% CI 0.28 to 0.81 ) for endurance athletes, $0.67(0.50$ to 0.92$)$ for mixed sports athletes, and $0.69(0.49$ to 0.98$)$ for power sports athletes. All sports groups had low age adjusted odds ratios for current chronic productive cough compared with controls (table 3).

Age, smoking, occupational group, and exposure to chemicals were included in fixed logistic regression models with the athletic groups to study their associations with the pulmonary diseases and symptoms (table 3 ). According to these models, expected associations between the pulmonary diseases and confounders were seen. The adjusted odds ratios are shown in table 3. There was an increase with age in the risk of having asthma ( $4 \%$ per year, $95 \%$ CI $1 \%$ to $6 \%$ ), but there was no increase in the prevalence of asthma among athletes compared with controls.

Among the group answering the questionnaire, asthma was documented in the reimbursable medication register for four $(2 \cdot 3 \%)$ of the endurance athletes, nine $(1.4 \%)$ of the mixed sports athletes, six $(1.4 \%)$ of the power sports athletes, and $20(2 \cdot 6 \%)$ of the controls. Among the responders to the questionnaire, $56 \cdot 1 \%$ ( 32 of 57 ) of those who reported asthma also had a reimbursable medication record, while $0.3 \%$ (seven of 2002 ) of subjects who did not report asthma in the questionnaire had reimbursable medication recorded.

According to the death certificates, two controls but none of the athletes died of asthma between 1936 and 1985 .

Table 3 Odds ratios (OR) and their 95\% confidence intervals (CI) for the lifetime occurrence of chronic bronchitis, emphysema, asthma, and current chronic productive cough in the different athletic groups compared with controls (adjusted for age, and for age, smoking, occupational group, and exposure to chemicals)

\begin{tabular}{|c|c|c|c|c|c|c|c|c|}
\hline \multirow[t]{2}{*}{ Sport } & \multicolumn{4}{|l|}{ Age adjusted } & \multicolumn{4}{|c|}{ Adjusted for age, smoking, occupational group and exposure to chemicals } \\
\hline & Asthma & $\begin{array}{l}\text { Chronic } \\
\text { bronchitis }\end{array}$ & Emphysema & $\begin{array}{l}\text { Current chronic } \\
\text { productive cough }\end{array}$ & Asthma & $\begin{array}{l}\text { Chronic } \\
\text { bronchitis }\end{array}$ & Emphysema & $\begin{array}{l}\text { Current chronic } \\
\text { productive cough }\end{array}$ \\
\hline Endurance sports & $\begin{array}{l}0.68 \\
(0.25 \text { to } 1.81)\end{array}$ & $\begin{array}{l}0.41^{*} \\
(0.20 \text { to } 0.85)\end{array}$ & $\begin{array}{l}0.48 \\
(0.22 \text { to } 1.03)\end{array}$ & $\begin{array}{l}0.29^{*} \\
(0 \cdot 10 \text { to } 0.83)\end{array}$ & $\begin{array}{l}0.64 \\
(0.21 \text { to } 1.97)\end{array}$ & $\begin{array}{l}0.48 \\
(0 \cdot 21-1 \cdot 10)\end{array}$ & $\begin{array}{l}0.73 \\
(0.31 \text { to } 1.72)\end{array}$ & $\begin{array}{l}0.27 \\
(0.06 \text { to } 1 \cdot 18)\end{array}$ \\
\hline Mixed sports & $\begin{array}{l}0.64 \\
(0.34 \text { to } 1 \cdot 21)\end{array}$ & $\begin{array}{l}0.77 \\
(0.53 \text { to } 1 \cdot 10)\end{array}$ & $\begin{array}{l}0.34 \ddagger \\
(0.19 \text { to } 0.60)\end{array}$ & $\begin{array}{l}0.33 \ddagger \\
(0.18 \text { to } 0.61)\end{array}$ & $\begin{array}{l}0.68 \\
(0.32 \text { to } 1.41)\end{array}$ & $\begin{array}{l}1.07 \\
(0.70 \text { to } 1.64)\end{array}$ & $\begin{array}{l}0.46^{*} \\
(0.23 \text { to } 0.92)\end{array}$ & $\begin{array}{l}0.61 \\
(0.31 \text { to } 1.23)\end{array}$ \\
\hline Power sports & $\begin{array}{l}0.60 \\
(0.29 \text { to } 1.26)\end{array}$ & $\begin{array}{l}0.83 \\
(0.55 \text { to } 1.24)\end{array}$ & $\begin{array}{l}0.45 \dagger \\
(0.25 \text { to } 0.80)\end{array}$ & $\begin{array}{l}0.55^{*} \\
(0.31 \text { to } 0.99)\end{array}$ & $\begin{array}{l}0.68 \\
(0.31 \text { to } 1.50)\end{array}$ & $\begin{array}{l}0.94 \\
(0.59 \text { to } 1.50)\end{array}$ & $\begin{array}{l}0.43^{*} \\
(0.21 \text { to } 0.87)\end{array}$ & $\begin{array}{l}0.46 \\
(0.21 \text { to } 1.01)\end{array}$ \\
\hline Total & $\begin{array}{l}0.63 \\
(0.37 \text { to } 1.07)\end{array}$ & $\begin{array}{l}0.73 \\
(0.54 \text { to } 1 \cdot 00)\end{array}$ & $\begin{array}{l}0.40 \ddagger \\
(0.26 \text { to } 0.61)\end{array}$ & $\begin{array}{l}0.40 \ddagger \\
(0.25 \text { to } 0.63)\end{array}$ & $\begin{array}{l}0.67 \\
(0.37 \text { to } 1.23)\end{array}$ & $\begin{array}{l}0.94 \\
(0.65 \text { to } 1.35)\end{array}$ & $\begin{array}{l}0.49 \dagger \\
(0.29 \text { to } 0.83)\end{array}$ & $\begin{array}{l}0.50^{*} \\
(0.28 \text { to } 0.88)\end{array}$ \\
\hline Controls & $1 \cdot 0$ & $1 \cdot 0$ & $1 \cdot 0$ & $1 \cdot 0$ & $1 \cdot 0$ & $1 \cdot 0$ & $1 \cdot 0$ & $1 \cdot 0$ \\
\hline
\end{tabular}

${ }^{*} \mathrm{p}<0.05 ;+\mathrm{p}<0.01 ; \ddagger \mathrm{p}<0.001$ versus controls. 


\section{Discussion}

Our study was designed to compare pulmonary diseases (asthma, chronic bronchitis, emphysema) as diagnosed by physicians in male former top level athletes in various types of sport with their controls. As expected, the occurrence of the pulmonary diseases was associated with age, smoking habits, and occupational group. ${ }^{16}$ After adjusting for these variables, mixed sports and power sports athletes had lower odds ratios for emphysema, and endurance sports athletes had a lower odds ratio for pulmonary disease, than controls. We did not find an increase in the prevalence of asthma among endurance athletes who had trained in a cold environment.

At the age of 20 all the controls were classified as fully fit for military service. Our study has the limitations concerning the precise recording of the diseases by questionnaire, but methodological bias behind the higher occurrence of diseases in the controls is unlikely. However, there may have been selection bias at the beginning of our study as subjects with suboptimal ventilatory function as young adults may have been incapable of becoming top athletes in endurance sports, thus reducing the prevalence of later chronic pulmonary disease. In particular, exercise induced asthma in a child when no effective prophylactic treatment was available would tend to impair athletic performance and result in exclusion from the top athlete group. The fact that emphysema occurs less frequently in athletes probably supports a "healthy athlete effect". On the other hand, some former athletes may seek treatment more actively than controls because of their more demanding lifestyle. ${ }^{10}$

The reimbursable medication register confirmed our questionnaire findings on the occurrence of asthma. As expected, more asthma was reported via the questionnaire than in the reimbursable medication register which only documents the more severe cases. Use of the reimbursable medication register also revealed that the occurrence of asthma among the athletes who did not respond to the questionnaire (two records in 236 athletes, both in mixed sports) was no higher than in non-responding controls (five records in 233 controls). Study of the death certificates confirmed that there were no deaths due to severe asthma among athletes between 1936 and 1985 .

According to the 1985 questionnaire, $68 \%$ of endurance athletes, $63 \%$ of mixed sports athletes, $60 \%$ of power sports athletes, and $17 \%$ of the controls had engaged in leisure time physical activity or competitive sports throughout their adult life, ${ }^{10}$ which suggests that the group differences in patterns of long term physical activity tend to persist long after a competitive career in their youth. Exposure to cold air was common among our endurance athletes, but the proportion of time spent training and playing outdoors and indoors among mixed sports athletes could not be documented in detail. We therefore classified the athletes into three groups based on the type of training and maximal oxygen uptake documented among athletes of each sport. ${ }^{1011}$
Physical exercise and cold air are both strong provoking factors for asthma, especially in combination. ${ }^{47}$ However, our findings agree with some earlier studies in that there was no excess prevalence of chronic asthma among athletes compared with the general population. ${ }^{1819}$ In addition, the risk of asthma for outdoor endurance athletes was similar to that for indoor power athletes (table 3). Our study does not support the hypothesis that athletes training in cold environments have a higher risk of acquiring chronic asthma. It does not exclude the possibility that athletes who use asthma drugs and participate in sports with greater exposure to air pollutants or cold may have a higher risk of developing the condition. Bronchial reactivity, which occurs frequently in healthy and asthmatic subjects after inhaling cold air ${ }^{2021}$ as well as in athletes when training in a cold environment, may be a protective mechanism.

Most chronic obstructive lung disease is initiated, or at least complicated, by the inhalation of particles and gases including cigarette smoke. The amount of inhaled material that reaches the airways and parenchyma is related to the ventilation level and pattern of breathing. As a consequence of the exercise-related switch from nose to mouth breathing and the accompanying increase in rate of flow, the inhaled substances reaching the lower airways and alveolar regions can increase by many hundred fold. ${ }^{22}$ Elite athletes may thus be bioindicators of the higher levels of air pollution during the last decade. Exposure to low concentrations of various combined allergens may contribute to bronchial reactivity. ${ }^{23}$

We found a lower age adjusted incidence of pulmonary disease in former athletes than in non-athletic controls. Much of the difference was explained by occupational group, smoking, and exposure to chemicals. Compared with controls, mixed sports and power sports athletes had a lower adjusted odds ratio for emphysema, and endurance sports athletes for the presence of pulmonary disease. Our study design did not permit us to draw precise conclusions about whether exercise itself or other lifestyle factors are the most important protective mechanisms, nor was it possible to exclude genetic selection. We conclude that the lifetime occurrence of asthma or other pulmonary diseases was not increased among former elite athletes up to 1985 , and that exercise alone is not a strong candidate for explaining the apparent increase in the prevalence of asthma recently reported among top level skiers and runners in Nordic countries.

The authors thank Dr Heikki Tikkanen (Helsinki, Finland) for his expert comments during preparation of the manuscript. The work was supported by grants from Yrjö Jahnsson Foundation and the Finnish Ministry of Education.

1 Voy RO. The US Olympic committee experience with exercise-induced bronchospasm. Med Sci Sports Exerc 1984;18:324-30.

2 Weiler JM, Metzger WJ, Donnelly AL, Crowley ET, Sharat MD. Prevalence of bronchial hyperresponsiveness in highly trained athletes. Chest 1986;90:23-8.

3 Gomes I, Figueiredo MM, Oliveira J, Almeida J, Coelho M, Marques A. Bronchial responsiveness to inhaled methacoline in well trained runners. Eur Respir $\mathcal{F}_{1992}$ 5(Suppl 15):455. 
4 Strauss RH, McFadden ER Jr, Ingram RH Jr, Jaeger JJ. Enhancement of exercise-induced asthma by cold air. $N$ Engl f Med 1977;297:743-7.

5 Larsson K, Ohlsén P, Larsson L, Malmberg P, Rydström PO, Ulriksen $\mathrm{H}$. High prevalence of ast country skiers. BM7 1993;307:1326-9.

6 Heir T, Oseid S. Self-reported asthma and exercise-induced asthma symptoms in high-level competitive cross-country skiers. Scand f Med Sci Sports 1994;4:128-33.

7 Tikkanen HO, Helenius I. Asthma in runners (letter). BMf 1994;309:1087.

8 Heir T. Longitudinal variations in bronchial responsiveness in cross-country skiers and control subjects. Scand $\mathcal{F ~ M e d ~}$ Sci Sports 1994;4:134-9.

9 Kraan J, Koeter GH, Mark WVD, Sluiter HJ, Vries KD Changes in bronchial hyperreactivity induced by 4 weeks of treatment with antiasthmatic drugs in patients with allergic asthma: a comparison between budesonide and terbutaline. 7 Allergy Clin Immunol 1985;76:628-36.

10 Sarna S, Sahi T, Koskenvuo M, Kaprio J. Increased life expectancy of world class male athletes. Med Sci Sport Exerc 1993;25:237-44

11 Åstrand P-O, Rodahl K, eds. Textbook of work physiology. 3rd ed. New York: McGraw-Hill, 1986:412-5.

12 Medical Research Council's Committee on the Aetiology of Chronic Bronchitis. Standardized questionnaires on respiratory symptoms. BMF 1960;2:1665.

13 Vesterinen E, Pukkala E, Timonen T, Aromaa A. Cancer incidence among 78000 asthmatic patients. Int $\mathcal{F}$ Epidemiol 1993;22:976-82.
14 Central Statistical Office. Alphabetical list of occupations and classification of social class. In Finnish. ( $\mathrm{Ti}$ lastokeskus. Aakkosellinen ammattihakemisto sekä sosiaaliryhmittely, 1972). Helsinki, 1972.

15 Kaprio J, Koskenvuo M, Sarna S. Cigarette smoking, use of alcohol, and leisure-time physical activity among like37-46.
sexed adult male twins. Prog Clin Biol Res 1981;69C:

16 Fletcher C, Peto R. The natural history of chronic airflow obstruction. BMf 1977;1:1645-8.

17 McFadden ER. Pathogenesis of asthma. F Allergy Clin Immunol 1984;73:413-24.

18 Rice SG, Bierman CW, Shapiro GG, Furukawa CT, Pierson WE. Identification of exercise-induced asthma among intercollegiate athletes. Ann Allergy 1985;55:790-3.

19 Vathenen AS, Knox AJ, Higgins BG, Britton JR, Tattersfield $\mathrm{AE}$. Rebound increase in bronchial responsiveness after treatment with inhaled terbutaline. Lancet 1988;i:554-8 20 Amariv I, Plit M. Temperature and relative humidity response to inhaled histamine in normal subjects. Am Rer Respir Dis 1989140:1416-20.

21 Dosman JA, Hodgson WC, Cockcroft DW. Effect of cold air on bronchial response to inhaled histamine in patients with asthma. Am Rev Respir Dis 1991;144:45-50.

22 Brain JD, Skornik WA, Spaulding GL, Harbison M. The effects of exercise on inhalation of particles and gases. In Brain JD, Beck BD, Warren AJ, Shaikh RA eds. Variation in susceptibility to inhaled pollutants. Baltimore: The Hopkins University Press, 1988:204-20.

23 Devalia JL, Rusznak C, Herdman MJ, Trigg CJ, Tarraf $\mathrm{H}$ Davies RJ. Effect of nitrogen dioxide and sulphur dioxide on airway response of mild asthmatic patients to allergen inhalation. Lancet 1994;344:1668-71. 